\title{
Finding a way towards high-quality, accessible tourism: the role of digital ecosystems
}

\author{
Fabio Cassia, Paola Castellani, Chiara Rossato and Claudio Baccarani \\ Department of Business Administration, University of Verona, Verona, Italy
}

\begin{abstract}
Purpose - Despite a growing interest in accessible tourism, delivering high-quality tourism experiences to people with disabilities $(\mathrm{PwD})$ remains a major challenge. Beyond a number of acknowledged barriers (e.g. cultural, architectural, relational), the main issue is the lack of coordination amongst the many actors participating in the co-creation of tourism experiences. This paper intends to advance available knowledge on this issue by conceptually suggesting a solution that draws on the concepts of the tourism experience and digital ecosystems. Design/methodology/approach - This paper is developed as a conceptual contribution, drawing also on an illustrative example that considers a tourist with mobility disability as the focal actor.

Findings - The results indicate that a digital ecosystem could contribute to making tourism locations more accessible by enabling information sharing and coordination amongst all actors that co-create the tourism experiences. Moreover, the analysis underlines that tourism locations should be designed to be useable by all people, drawing on the principles of the universal design.

Research limitations/implications - This paper describes a path to fostering accessible tourism, drawing on local authorities, particularly municipalities and universities. The suggested solution would benefit from future empirical analyses to assess its strengths and weaknesses.

Originality/value - By drawing on the concept of digital ecosystems, this paper is amongst the first studies to suggest a path to making tourism locations more accessible to all tourists (with or without disabilities) based on technology.
\end{abstract}

Keywords Accessible tourism, Perceived quality, Service ecosystems, Digital ecosystems

Paper type Conceptual paper

\section{Introduction}

Since the United Nations (1975) created the Declaration on the Rights of Disabled Persons, there has been increasing interest in the participation of people with disabilities $(\mathrm{PwD})$ in tourism. During the current coronavirus disease 2019 (COVID-19) crisis, the United Nations World Tourism Organization (UNWTO) has affirmed that "people with disabilities and seniors are heavily affected by COVID19 [and that] the recovery should include accessibility as a central pillar in measures to improve [tourist] destinations" offer and competitiveness' (UNWTO, 2020).

Over the years, there has been increasing academic interest in this topic, moving from a focus on "disability and tourism" to "accessible tourism" (Darcy et al., 2020). Despite the remarkable linguistic and conceptual fragmentation characterising the studies on this topic (Gillovic et al., 2018), there is general agreement that accessible tourism should seek to ensure that tourism is developed with people of all abilities in mind and can be consumed by people of all abilities (Scheyvens and Biddulph, 2018). However, the focal issue should not be simply the availability of infrastructure enabling travel to a destination but also the opportunity to truly experience the destination, which requires the development of accessible tourism experiences (Darcy et al., 2020). In fact, as shown by available models, travelling to the destination

(C) Fabio Cassia, Paola Castellani, Chiara Rossato and Claudio Baccarani. Published by Emerald Publishing Limited. This article is published under the Creative Commons Attribution (CC BY 4.0) licence. Anyone may reproduce, distribute, translate and create derivative works of this article (for both commercial and non-commercial purposes), subject to full attribution to the original publication and authors. The full terms of this licence may be seen at http://creativecommons.org/licences/by/4.0/legalcode

A way towards accessible tourism

Received 23 March 2020 Revised 6 June 2020 Accepted 30 June 2020

.


TQM

33,1

206 represents only one of the several stages of a holiday and it is necessary to adopt a wider approach that aims to design accessible destination experiences (Michopoulou et al., 2020).

Research has suggested that stakeholder collaboration is essential for the development of accessible tourism destinations, but the fragmentation of the hospitality and tourism industry makes delivering high-quality experiences for $\mathrm{PwD}$ at the destination level complex and challenging (Buhalis and Darcy, 2011; Nyanjom et al., 2018). Effective collaboration amongst stakeholders to enable accessible tourism would require several elements: control and coordination, collaboration and integration, clarity of roles and responsibilities, communication, and focus on access and inclusion (Nyanjom et al., 2018).

Drawing on these premises, the purpose of this paper is to contribute to the call for the academic community to assist in creating understanding of how to achieve more accessible tourism (Darcy et al., 2020) by exploring the role that technology may play in enabling the design of accessible destination experiences. Studies on technology within the context of accessible tourism are limited, and focus on specific issues such as compliance with web content accessibility guidelines (Naniopoulos et al., 2016). However, research has not developed a comprehensive perspective based on digital ecosystems to support the cocreation of accessible tourism experiences.

In detail, this study presents a conceptual contribution that combines the stream of literature related to accessible tourism and service ecosystems to highlight the role of technology in enabling the co-creation of valuable tourism experiences for PwD. Developing a conceptual contribution involves a process of understanding a situation abstractly by identifying patterns or connections and key underlying properties (MacInnis, 2011; Xin et al., 2013). In particular, we use the so-called "integrating approach", which "involves finding links or similarities that connect previously disparate entities; it involves seeing a new whole" (MacInnis, 2011, p. 146). Thus, we examine how the design and provision of accessible experiences in a destination ecosystem can be successfully enabled by technology.

The remainder of the paper is structured as follows. We first provide a review of the two streams of literature as a starting point for the arguments and analyses that follow. In detail, we begin by providing an introduction to accessible tourism, followed by an overview of the tourism experience and tourism ecosystems in light of the digital revolution. These two streams of literature are then jointly applied to the context of tourists with mobility disability to identify the form and role of the tourism ecosystem in this specific context. From this analysis, a discussion about the barriers to accessible tourism and the need for digital ecosystems is derived. Recommendations and conclusions complete the paper.

\section{Accessible tourism}

Accessible tourism is a "form of tourism that involves collaborative processes between stakeholders that enables people with access requirements, including mobility, vision, hearing and cognitive dimensions of access, to function independently and with equity and dignity through the delivery of universally designed tourism products, services and environments" (Buhalis and Darcy, 2011, p. 10). This definition, which is the most popular and widely accepted, is the result of a rich debate that has emerged over the years about the content and terminology pertinent to accessible tourism, as documented by Gillovic et al.'s (2018) detailed review on the subject.

PwD are the primary beneficiaries of accessible tourism even if, as Darcy and Dickson (2009) note, everyone at some stage in their lives will have some temporary or permanent access requirements. The underlying idea of accessible tourism is that everyone has the right to travel (UNWTO, 2001) to satisfy a number of needs felt differently by every person, for example, the need to enrich personal knowledge by experiencing the local culture of a visited location (Stone and Petrick, 2013) or the need to appreciate the diversity and beauty of locations explored with curiosity (Foubert, 2018). According to the estimations provided by 
the 2011 World Report on Disability (World Health Organisation [WHO], 2011), more than one billion people ( $15 \%$ of the world's population) has a severe or moderate disability. Recent estimations (United Nations Statistics Division, 2020) indicate that there are significantly high percentages of $\mathrm{PwD}$ for some countries (e.g. United Kingdom: 20.7\%) and demonstrate that walking disability is the most recurrent type of impairment (i.e. this type of disability affects $7.6 \%$ of the female and $5.6 \%$ of the male population of the United States).

Drawing on the World Health Organisation's classification, tourism studies separate the broad group of PwD into sub-groups according to the specific types of disability and the related access requirements. In detail, tourism studies (Alén et al., 2012; Buhalis and Darcy, 2011) usually distinguish the following types of disabilities: physical or mobility disability; cognitive or psychological disability (e.g. mental illness, intellectual disability); sensory disability (e.g. visual, hearing, communication, speech); hidden disability (e.g. those caused by allergies or epilepsy) and multiple disabilities. For each type of disability, the International Classification of Functioning, Disability and Health offers a highly detailed description of the related impairments and effects on activities and participation (WHO, 2001). These classifications and descriptions also serve as valuable sources for tourism researchers and managers (Alén et al., 2012).

The awareness of the importance of examining and promoting accessible tourism has grown since the 1975 United Nation's Declaration on the Rights of Disabled Persons (United Nations, 1975). However, available knowledge on this topic remains limited (Darcy et al., 2020) and the tourism industry has not progressed sufficiently in providing the market with accessible tourism products (Bowtell, 2015). Such slow development may be party related to the complexity and variety of access requirements, so that it is difficult to develop possible solutions for the needs of people from all groups and with different levels of disability (Altinay et al.,2016).

In addition to some perspective articles (e.g. Darcy et al., 2020; Michopoulou et al., 2020), research in this field has explored the issue of information accessibility. For example, Altinay et al. (2016) examine how PwD can access websites and social media pages of travel agencies or other institutions to obtain travel-related information. Similarly, Rumetshofer and Wöß (2004) explore PwD accessibility to tourism websites and information systems and to information about tourism infrastructure (e.g. transportation, accommodation). They also note that technology could support personalisation mechanisms based on the specific accessibility requirements of the user. Overall, the focus of this kind of analysis is on the technical aspects of accessible tourism in relation to web content usability and accessibility.

Other studies consider accessible tourism from the perspective of tourism offerings (i.e. tourism businesses and destinations). Alén et al. (2012) note that $\mathrm{PwD}$ represent a large but also not sufficiently explored market segment. Bowtell (2015) analyses the potential value of the accessible tourism market and the related perceptions of travel and leisure companies. Bowtell (2015) finds that PwD are being served poorly by the tourism providers and that less than $50 \%$ of tourism operators sell products to tourists with disabilities. In relation to destination management, Darcy and Dickson (2009) highlight the need to provide PwD with information about the destination to enable these customers to make informed decisions. They also remark that destinations should move beyond the simple removal of physical barriers by designing, planning, providing and communicating accessible experiences. In further detail, Vila et al. (2015) analyse the factors that determine a destination's competitiveness in the accessible tourism market and identify different intensities with which destinations are working to create accessibility. Finally, several studies consider specific projects for accessible tourism that have been implemented in specific destinations. Amongst them, Naniopoulos et al. (2016) describe an initiative in the Drama (Greece) and Mersin (Turkey) undertaken to increase the accessibility to tourism infrastructure for PwD (mostly in consideration of mobility disability).

Overall, the review of studies about accessible tourism suggests three main limitations in research. First, previous work has focussed more on the structure (e.g. physical barriers and 
TQM

33,1

208

infrastructure) of enabling accessible tourism than on the processes of accessible tourism (i.e. creating tourism experiences). Second, even when considering the destination level, the focus is on specific initiatives taken by one or more actors rather than on comprehensive and coordinated initiatives to enable seamless accessible tourism experiences. Third, research in this area suffers from an outdated view of technology, which is mainly conceived in relation to technical accessibility to online information. Thus, the role of technology in enabling a digital ecosystem that facilitates the co-creation of accessible tourism experiences is completely overlooked. In this paper, we contend that knowledge about accessible tourism can be advanced by embracing the concepts of customer (tourist) experience and (digital) service ecosystems. The next paragraph provides an overview on these concepts.

\section{Tourism experience and tourism ecosystems in light of the digital revolution} In the past two decades, tourism has been characterised by a major shift from tourism products to tourism experiences (Jorgenson et al., 2019; Park and Santos, 2017), which are actively co-created by tourists (Campos et al., 2018). This shift draws on a wider evolution occurring in the management literature from an approach based on the provision of products to an approach based on the co-creation of customer experiences (Forlani and Pencarelli, 2019). As revealed by a systematic literature review (Forlani and Pencarelli, 2019), studies about co-creation and value co-creation have play a primary role in the experience-related research, and within this stream of literature, the sub-areas of tourism, leisure and hospitality management clearly stand out.

The growing focus on value co-creation is driven by the increasing popularity of service dominant logic (S-D logic) (Vargo and Lusch, 2004, 2008, 2017), which serves as the theoretical framework for much of the research about experience co-creation in tourism studies (Campos et al., 2018; Chathoth et al., 2016). S-D logic suggests that service is the fundamental basis of exchange (Vargo and Lusch, 2008, 2017). That is, co-creating actors integrate their specialised skills and knowledge and engage in service-for-service exchanges for the benefit of other actors (Vargo and Lusch, 2008). Thus, S-D logic particularly emphasises the role of operant resources, which are those resources (e.g. skills and knowledge) that can act on other resources (e.g. goods, labelled as operand resources) to create a benefit (Lusch and Vargo, 2014; Vargo and Lusch, 2004). In addition, according to S-D logic, customers are no longer considered the passive recipients of a firm's offering but play an active role as resource integrators (Vargo and Lusch, 2004). Hence, both the customer and the firm are operant resources and value is always co-created and experientially determined (Vargo and Lusch, 2016).

While the initial conceptualisations of S-D logic focussed on the micro level, involving the firm and the customers, further theoretical advancements have suggested that value cocreation can also be examined within ecosystems at the meso level (i.e. the mid-range level such as a destination) and the macro level (i.e. in broad society) (Chandler and Vargo, 2011). A service ecosystem is defined as a relatively self-contained, self-adjusting system of resourceintegrating actors connected by shared institutional arrangements and mutual value creation' (Vargo and Lusch, 2016, pp. 10-11).

Moreover, research in the S-D logic stream of literature has been examining how technology changes how value is co-created and experienced by the customer within service ecosystems. In particular, Akaka and Vargo (2014) highlight that technology actively contributes to the value co-creation processes. Additionally, Storbacka et al. (2016) argue that technology can support engagement platforms, through which actors can contribute and connect the resources they have that are needed for value co-creation.

The strict interrelationships between tourism experience co-creation and technology is also a building block of smart tourism and smart tourism ecosystems (Barile et al., 2017). 
In fact, technology represents the main driver of change in tourism, which is evolving towards creating smart tourism experiences (Gretzel et al., 2015). The effects of this transformation can be understood both from the demand side and from the offering side. From the demand side, technology affects customer (tourist) experiences before, during and after the trip, so that traditional travellers are transformed into digital or smart travellers (Pencarelli, 2019). In the pre-trip stage, tourists have access to a wide range of potential alternative offerings and information, such as the information provided by online reviews, and can even test available tourism products by using augmented or virtual reality (Cranmer et al., 2020; Pencarelli, 2019). Technologies also enhance the tourism experience during and after the trip by allowing tourists to access and share valuable content through social media such as social networks and blogs (Law et al., 2018; Sotiriadis, 2017).

From the offering side, technology is increasingly enabling tourism companies and the other actors in the tourism value ecosystem to support more effective tourism experiences (Pencarelli, 2019). An example of how technology can facilitate co-creation amongst the actors of a tourism destination is provided by Cabiddu et al. (2013), who examine the case of Portale Sardegna (Italy).

Interestingly, three different views of the relationships between ecosystem institutions and technology in tourism have emerged: (1) institutions prepare the ground for technology development; (2) institutions and technology are at the same level and both influence innovation and (3) technology shapes institutions (i.e. technology drives institutions and market changes) (Barile et al., 2017). In fact, while technology has been usually considered an operand resource (i.e. an output), recent conceptualisations view technology also as an operant resource (i.e. a process) that is able to influence ecosystems and value co-creation (Akaka and Vargo, 2014).

While this view and the perspective of broader ecosystems have gained remarkable popularity in tourism studies, they have not yet been applied to research on accessible tourism. To highlight the need for this comprehensive approach to research on creating accessibility tourism, the study now explores tourism experiences from the perspective of a person with mobility disability.

\section{Tourism experience and tourism ecosystem from perspective of tourists with mobility disability}

\subsection{Mapping the tourism experience through the tourism customer journey}

The tourism customer journey (TCJ) involves mapping the entire journey of a tourist, outlining all the stages a person goes through when experiencing the need to move for tourism purposes (Astrøm, 2020). The TCJ draws on the more general concept of the customer journey, which is the "process a customer goes through, across all stages and touch points, that makes up the customer experience" (Lemon and Verhoef, 2016, p. 71). Mapping customer journeys is a popular and effective way to grasp the entire tourism customer experience (Rosenbaum et al., 2017). If the tourism product as a whole was offered by one single company, the general customer journey concept could be easily applied to tourism in the same way as it is applied to other kinds of services (e.g. banking, retail and insurance services). However, as will be discussed shortly, tourism is a more complex service because of the number and variety of co-creating actors and the relationships amongst them.

Here, we apply the TCJ to the context of people with mobility disability. A similar analysis could be applied to people with other disabilities (Alén et al., 2012), resulting in different and specific types of TCJs. Given the complexity of applying a contextual study to all types of disabilities, this study focusses only on people with mobility disability, but the same method of analysis could be easily extended and replicated.

From the very beginning of the TCJ, even when individuals are planning their holiday, they will encounter a series of actors, whose number will dramatically increase in the subsequent stages of the journey (Buhalis, 2000; Saraniemi and Kylänen, 2011). This is 
TQM

33,1

\section{0}

because tourism involves a complex ecosystem that has many actors who influence to a greater or lesser extent the experience perceived by individuals during their journey (Gretzel et al., 2016). The quality delivered by each actor clearly influences the overall quality of the tourist's overall experience (Ciasullo, 2017). Sometimes this phenomenon is emphasised because the quality performance of one provider has a spillover effect on the customer's evaluation of the quality performance of other components of (or actors in) the tourism ecosystem (Bourdeau et al., 2007). That is, a negative performance in one part of the journey may have a negative halo effect on the entire journey, considering that the tourist (beyond being the focal actor of the ecosystem) (Storbacka et al., 2016) is the only actor to see all the components of the ecosystem. Similarly, a positive performance in one of the moments of truth (Normann, 2001) has the potential to compensate for a series of negative performances in other parts of the journey.

Overall, there is a remarkable risk of tourist dissatisfaction, which is heightened when the person undertaking the journey has some form of disabilities, such as when they have reduced mobility. These arguments can be illustrated through the construction of the TCJ for a holiday that is independently conceived and designed by a person with mobility disability who has time to spend in a destination to be selected and does not want to rely on standardised offerings delivered by tour operators. For this purpose, we draw on the general framework suggested by Baccarani and Cassia (2017), according to which a holiday is articulated and occurs in the following four main stages (Figure 1):

(1) destination choice and trip design;

(2) outbound trip;

(3) staying at the destination;

(4) transfer to another destination or return home.

Each of the four stages of the TCJ develops through the processes that are outlined below. The points marked with the sign $(*)$ in the following list represent critical aspects for people with mobility disability because they can entail various problems related to accessibility because of the presence of architectural, communication, cultural, technological and relational barriers.

The first stage of the TCJ - destination choice and trip design - encompasses the formation of a tourist's experiential expectations drawing on the following elements:

Figure 1.

Main stages of the tourism customer journey

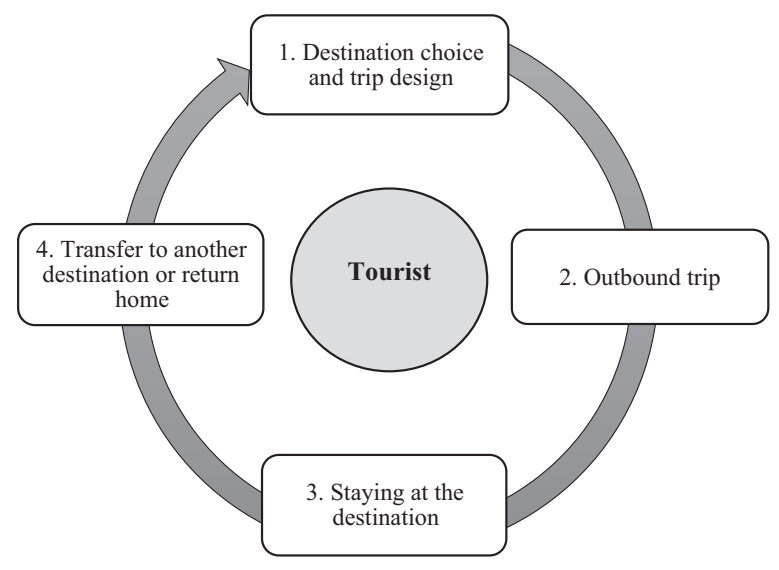


(1) time available for the journey,

(2) motivations triggering the need for the journey, accessible tourism

(3) any previous personal holiday experiences,

(4) any previous indirect holiday experiences (e.g. information collected online, online reviews and e-word-of-mouth),

(5) dialogue and interactions with disability organisations and associations,

(6) information available online or printed specialised magazines and publications,

(7) information available in promotional materials delivered by tourism destinations,

(8) means of transportation available and reservation of such transportation (*),

(9) type of accommodations available and reservation of such lodgings $(*)$,

(10) definition of a hierarchy of suitable destinations $(*)$.

The second stage of the TCJ - outbound trip - covers the most complex part of the holiday. In fact, the anticipated benefits of the planned holiday take shape during this stage. In the case that the tourist uses a personally owned means of transport suitable for their disability to reach the boarding point and that the travel is done by aeroplane, this stage includes the following elements:

(1) printing the boarding pass,

(2) estimating the time that they must leave home to reach the airport (this estimation is informed by customers' sensitivity to risk and the information available),

(3) preparing their luggage,

(4) planning which road or highways to take to reach the airport,

(5) stopping at rest areas to meet their needs or the needs of others or to comply with the requirements of the transport providers $(*)$,

(6) parking in an area near the airport (*),

(7) checking in their luggage $(*)$,

(8) reaching the boarding point $(*)$,

(9) complying with any safety control procedures $(*)$,

(10) waiting at a boarding gate $(*)$,

(11) boarding the aeroplane (*),

(12) flying to the destination $(*)$,

(13) disembarking and claiming their luggage (*),

(14) searching for a local means of transport to reach the accommodation facility (*),

(15) arriving and being welcomed at the accommodation facility (*).

The third stage of the TCJ - staying at the destination - represents the core of the holiday with all that a person desired for their time away on holiday. This is a stage of personal enhancement in relation to seeking knowledge, values and relationships. During this stage, the core value of the holiday emerges and is influenced, at least in the beginning, by the travel 
TQM

33,1

212

experience, which may increase or diminish the initial enthusiasm. This stage encompasses the following points and involves a variety of actors at the destination:

(1) planning itineraries, visits and activities that the tourists wish to engage in at the destination based on their previous knowledge and the information available to them,

(2) visiting cultural, artistic and natural sites in an area (*),

(3) forming relationships with the host community (*),

(4) selecting from a variety of foods and eateries on offer $(*)$,

(5) participating in local guided tours (e.g. wine tours) $\left(^{*}\right)$,

(6) using local means of transport (*),

(7) purchasing souvenirs.

The fourth stage of the TCJ - transfer to another place or return back home - is similar to stages two and three described above, and includes the overall evaluation of the perceived quality in relation to the expected quality developed in stage one.

In addition to the steps described above, which imply a variety of relationships between the tourist and several different actors, the context of a holiday is even more complex because tourist safety and care must be specifically assured, particularly for PwD. These conditions must be guaranteed by higher-level welfare systems, with which the tourism service network should be able to cooperate effectively.

In summary, in this TCJ the tourist benefits from a variety of services that globally support the creation of the tourism experience, which is phenomenologically determined and perceived by the beneficiary (i.e. the tourist) (Vargo and Lusch, 2016).

\subsection{Identifying the tourism ecosystem in relation to tourists with mobility disability}

This subsection identifies the actors that form the complex tourism ecosystem in its cocreation of the tourism experience. During each of the four stages of the TCJ, many different actors contribute to the formation of the overall tourist experience by delivering or not delivering the expected quality. In the tourist's experience, all these actors form a tourism service ecosystem, even if they represent only a set of services that the customer has assembled (Baccarani and Cassia, 2017). In fact, a service ecosystem implies a selfcontained, self-adjusting system of resource-integrating actors connected by shared institutional arrangements and mutual value creation (Vargo and Lusch, 2016). However, this level of coordination amongst all the actors involved in the co-creation of tourism experience does not yet exist. Below, we outline the actors involved in each of the four stages of the TCJ.

In the first stage, the tourist imagines, designs, plans and anticipates the pleasure of their holiday. To complete this stage, the tourist relies on the information provided by actors such as airlines and accommodation providers and interact with them directly or through intermediaries. For people with mobility disability, the dialogue and interactions with disability organisations and associations play an important role. As highlighted by the UNWTO, disabled peoples' organisations (DPOs) play a key role in accessible tourism because "they are mediators in understanding specific needs, existent barriers and the ways to bridge them" (UNWTO, 2020).

At this first stage of the TCJ (destination choice and trip design), quality is evaluated on the basis of the completeness and clarity of the information provided by multiple actors. All the actors involved in this first stage of the TCJ represent the holiday-design ecosystem (see Figure 3). 
In the second stage of the TCJ (outbound trip), at least the following 12 actors are involved, and this number could be even higher if a tourist decides to use public means of transport (instead of a personally owned means on transport):

(1) producers of publications or websites and intermediaries distributing information that guides the tourist in selecting the destination during the season in which the journey takes place;

(2) booking organisations through their websites;

(3) transport providers, including those preparing the service timetable;

(4) highways operators who have information about roadworks and any related delays;

(5) firms executing the roadworks who have information about any interruptions that may affect the roadworks and travel times;

(6) firms managing the rest areas and a variety of other services that may be required;

(7) firms managing the parking areas who may assist customers to reach their boarding point after having parked their vehicle;

(8) airport company that manages the departure airport that offers a welcome service and controls safety processes;

(9) airline that is responsible for checking in passengers, assigning boarding gates, flying times and delivering baggage;

(10) airport company that manages the arrival airport that offers welcome services and provides information to customers and about local means of transport;

(11) local transport service operators;

(12) accommodation services providers.

Therefore, a tourist interacts with at least 12 different co-creating actors during the second stage of the TCJ. These actors are connected in the tourist's mind but they are practically linked only through market relations and they do not coordinate their decisions and behaviours. Thus, it is unlikely that the tourist will be able to complete the second stage without experiencing some level of difficulty. For example, the tourist may miss the flight because of planned roadwork not being properly notified in advance or because of other unforeseen events. To evaluate the quality of the overall experience, the tourist considers all the components of this stage of the TCJ, comparing expected and actual quality. In particular, the tourist will appreciate the problem-solving capability of the actors. This second group of actors represents the travel ecosystem (see Figure 3).

In the third stage of the TCJ (staying at the destination), the tourist stays at the chosen destination where they interact with at least the following actors:

(1) firms who manage welcome and accommodation services;

(2) restaurateurs;

(3) local inhabitants (local community);

(4) local transport service operators;

(5) local merchants with their value propositions;

(6) agencies who organise local tours so that customers can explore local traditions, culture and products; 
TQM

33,1

\section{4}

(7) municipalities;

(8) organisations protecting tourists' safety and care.

This third stage of the TCJ has fewer actors than the second stage. However, the variety of actors is greater because during the tourist's stay at the destination, the tourist will engage in activities such as trying different types of food offerings to appreciate the local food culture, which means they will have contact and engage with more actors. Similarly, to explore local artistic, natural and cultural heritage, the tourist will select from a variety of opportunities that are available at the destination. In the third stage of the TCJ, the local community also plays a fundamental role in welcoming tourists and in co-creating their tourism experiences. In fact, in addition to the technical and functional-relational components of the quality delivered by local services (Grönroos, 1990; Kang and James, 2004), the welcoming atmosphere experienced at the destination plays a central role in the formation of the overall perceived quality (Nunkoo and Ramkissoon, 2011). All the actors involved in the third stage of the TCJ represent the staying at destination ecosystem (see Figure 3).

The fourth stage (transfer to another place or return back home) is a replication of the stages two and three outlined above and encompasses the tourist's comparison between the overall perceived quality and the expected quality developed in stage one.

The actors that populate the tourism service ecosystem are largely the same for tourists with and without disabilities. However, tourists with disabilities can select amongst a smaller number of offerings than tourists without disabilities. Moreover, actors are required to have adequate technical and relational skills to deliver tourism services to tourists with disabilities. Thus, tourists with disabilities must face greater difficulties in their travel-related choices because of the presence of several types of barriers (see Figure 2).

The tourism ecosystem described in this sub-section is depicted in Figure 3.

The quality of the tourism experience emerges from the relationships established within this tourism ecosystem through which resources are combined and value is co-created. Such relationships have different degrees of smoothness depending on the presence of several barriers.

\section{Barriers to accessible tourism: can digital ecosystems represent a solution?}

Drawing on the arguments developed so far, this section identifies in detail the barriers to fulfilling tourism experience co-creation for PwD. The intention of the discussion is to

Figure 2.

The tourism ecosystem

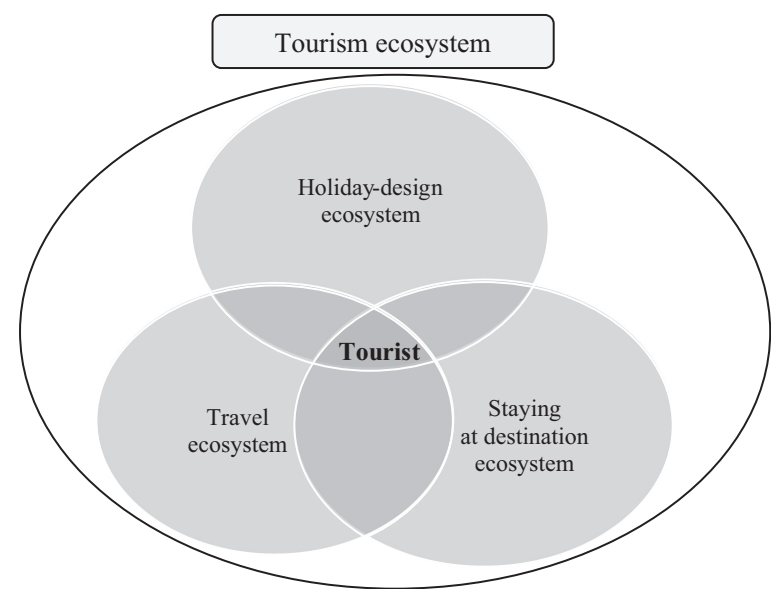




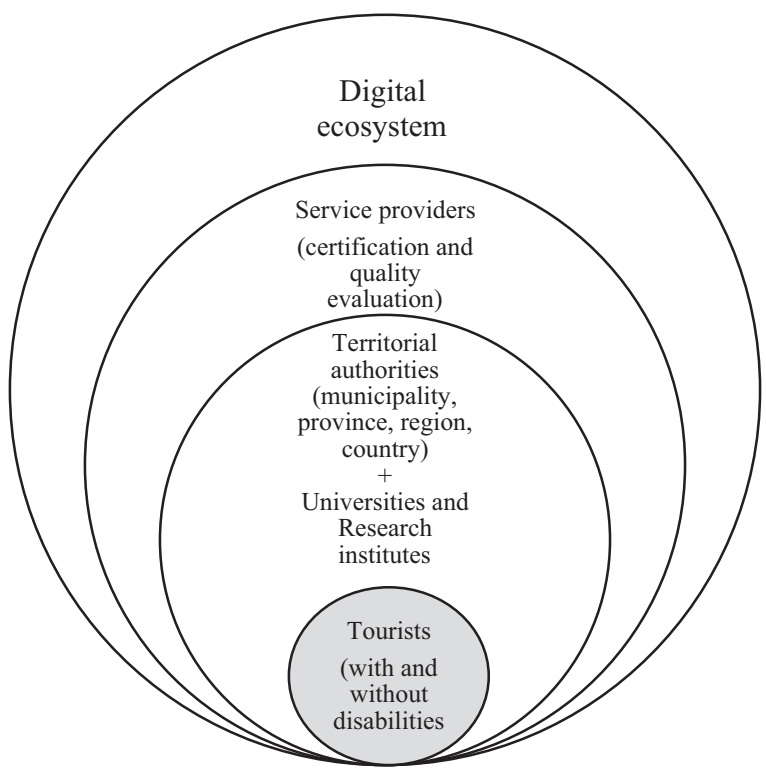

A way towards
accessible
tourism

understand whether and how digital ecosystems could represent a viable solution to such barriers. The identified relationships amongst the co-creating actors have not been harmonised to deliver the overall quality desired by the tourist because they are regulated by pure competitive mechanisms, emphasising the value of a specific part of the ecosystem instead of the value of the entire ecosystem. However, in tourism, competition amongst companies of the same sector can exist only once a territory as a whole is attractive. As highlighted in several studies (Baccarani et al., 2019; Barnes, 2004), the territory is not a physical space, but a highly complex viable subject emerging from all co-creations over time through the interactions between nature and human beings. Thus, the territory emerges from the relational synergies between the people who inhabit it and the environment.

Therefore, the stronger the synergies established in a certain location, the higher the location's attractiveness and value, which then make the location a platform in which individual actors can compete against each other with their propositions. That is, the longterm attractiveness of a territory and of a tourism destination derives from the actions of the entire ecosystem, within which the actors must aim to do their best through a continuous dialogue with the territorial ecosystem.

For this purpose, tourism must be conceived in a holistic manner by deploying planning efforts that involve all the actors of the ecosystem and engage all the potential beneficiaries of the tourism offering - be they are tourists with or without disabilities (Darcy et al., 2020). This perspective cannot ignore a series of barriers that determine biases in the co-creation of a location that provides tourism services for all tourists and particularly for those with mobility disability. In detail, the following barriers to accessible tourism can be identified (Gillovic et al., 2018; Michopoulou et al., 2020; Nyanjom et al., 2018):

(1) informational barriers;

(2) architectural barriers;

(3) political barriers; 
TQM

33,1

216

(4) cultural barriers;

(5) relational barriers;

(6) technological barriers;

(7) entrepreneurial myopia.

These barriers are outlined below from the perspective of $\mathrm{PwD}$. Informational barriers refer to the difficulties that a person with disabilities faces when desiring to autonomously evaluate and choose a means of transport, accommodation, a holiday itinerary or simple holiday activities such as shopping. While there is usually a great deal of information is available for such services, informational needs of $\mathrm{PwD}$ leads to higher levels of complexity. For example, even when information about tourism services is available it can difficult to verify.

Architectural barriers refer to the obstacles $\mathrm{PwD}$ encounter on holiday when engaging in activities such as accessing means of transport, moving in different locations, and using sidewalks and roads. Inconveniences related to architectural barriers can often also be experienced by people without disabilities (e.g. finding it difficult to understand the subway system) but the barriers are emphasised for PwD.

Architectural barriers are directly connected to political barriers, which refer to the needs of $\mathrm{PwD}$ in the context of a political agenda. While political discourses highlight the ideal of acting to eliminate architectural barriers, political actions are often guided by urgency, shorttermism and narrow-sighted electoral benefits.

Cultural barriers refer to the indifference that can characterise the behaviour of all people of all abilities (Gillovic et al, 2018) towards PwD. This barrier is manifest in factors such as the lack of respect for $\mathrm{PwD}$ parking slots.

Relational barriers refer to the general population viewing $\mathrm{PwD}$ from a self-righteous perspective, believing that the PwD cannot live a full life, even within the constraints of the experienced impairments.

Technological barriers refer to the speed of the technological change related to means of transport and communication, which can create difficult situations for those who do not keep up with the ongoing changes.

Entrepreneurial myopia refers to the inability to appreciate the size and value of the tourism market for PwD and of changes occurring in public opinion. This myopia is in tension with the ideals of sustainability provided by Agenda 2030 (United Nations, 2015), which explicitly highlights the need to promote sustainability and inclusivity and to empower $\mathrm{PwD}$ (e.g. points 11 and 23 of Agenda 2030) and by the Global Code of Ethics for Tourism (UNWTO, 2001), which states the "right to tourism" (article 7).

When accessible tourism experiences are designed, it is important to avoid ad-hoc solutions aimed exclusively at $\mathrm{PwD}$ (Scheyvens and Biddulph, 2018). Following the principles of universal design (Michopoulou et al., 2020), tourism providers should in fact enable experiences that are useable by all people, with or without disabilities. This approach is consistent with the idea that tourism carries a value that makes it a public service, interpreted as a service that should be assured for every member of communities that desire such services.

The question now arises of the assessment of the potential of digital ecosystems to remove the identified barriers and enable effective accessible tourism experience cocreation. While it is clear that technology cannot solve all the problems, we contend that it represents a valuable engine for such effective co-creation. As noted by Akaka and Vargo (2014), technology should be conceived as an operant resource able to bring about changes in ecosystems and influence value co-creation processes. The provision of a platform to support the engagement of actors involved in accessible tourism can thus represent a first 
step to first removing informational and relational barriers, and over time, smoothening other barriers (e.g. cultural barriers).

Thus, technology can enable the emergence of a digital ecosystem with tourists and their needs as the focal actors (Gretzel et al., 2015, 2016). Such an ecosystem could initially organise and coordinate suitable solutions to emerging PwD needs and issues by collecting and sharing the information concerning all the actors of the ecosystem.

Given that tourism is a service provided by a specific territory, the digital ecosystem should be led by the authorities in charge at the territorial level, whether a municipality, province, region or country. Given that the emerging ecosystems require rapid efficiency and effectiveness checks, it seems more appropriate that the process begins at the local territorial level and then extended (through imitation and adaptations) to higher levels.

Beyond authorities in charge at the territorial level, universities and other research institutes should play a central role in the design of a tourism ecosystem. These institutions should establish a dialogue with tourists, with $\mathrm{PwD}$ and with disability organisations and associations, without overlooking local inhabitants who are important for creating a warm and smooth welcoming. The emergence of the tourism ecosystem also draws on the constructive contributions of all the organisations representing the service providers who play a role in co-creating tourism experiences. The digital ecosystem should also be based on a series of incentives for firms that decide to be a part of the ecosystem, beyond a process of certification and evaluation of their delivered quality.

As a good starting point, municipalities could establish tourism departments that have the additional responsibility for the removal of mobility barriers. The viability of this choice is demonstrated by the experience of Verona, the first (and currently the only) municipality in Italy that has introduced such a department. For smaller municipalities, the digital ecosystem could be created at a higher level, such as in a consortium of municipalities, a province or a region. Figure 2 presents the main features of the tourism digital ecosystem.

Overall, the establishment of a digital ecosystem aims to make the territory an inclusive, warm and welcoming location where people want to live or stay. Hence, by providing an engagement platform, technology can act as an operant resource, disrupting the myopia guiding each actor's individual behaviours. An example of a digital ecosystem to support accessible tourism is the one being implemented by Explora, the destination management organisation of the Lombardy region (Italy). Explora has begun to establish a digital ecosystem (Ecosistema Digitale Turistico della Lombardia) through a platform that aims to support information sharing amongst the actors of Lombardy's tourism ecosystem. This ecosystem has not been created specifically to support accessible tourism. However, through this platform, operators could coordinate and harmonise the design of accessible tourism experiences, which would then be communicated and sold through the related web portal "inlombardia.it". This web portal currently hosts dozens of accessible tourism experiences; however, these are not conceived following the concept of the holistic ecosystem described in this paper. Nonetheless, the technological infrastructure that has been created has the ability to foster the future emergence of such a holistic accessible tourism ecosystem.

\section{Conclusions}

For several reasons, contributing to making tourism more accessible to PwD represents a priority for all the stakeholders involved in tourism, including those in the academic community. From the ethical perspective, every person should have the possibility to satisfy the fundamental right to travel. Moreover, accessible tourism has the potential to contribute to the competitiveness of tourism organisations and destinations, representing a valuable opportunity to enhance the wellbeing of the territory and its inhabitants (e.g. by creating new jobs). 
TQM

33,1

This paper aimed to advance knowledge and debate by developing arguments that support the key role of digital ecosystems. By acknowledging the role of technology as an operant (and not only as an operand) resource, this study indicates that technology itself can play a key role in shaping the ecosystem to support accessible tourism. However, despite its great potential, technology itself is ineffectual without political and social will.

Hence, the most critical step of the entire process along the suggested path is the first one, that is, deciding to start the process itself. For this purpose, the role of the territory with its public institutions is pivotal. Therefore, we recommend that territorial authorities and destination management organisations (where available), with the support of universities and research centres, take a leading role in developing an effective engagement platform around which the commitment of other actors can be motivated. For this purpose, it is important to be convinced that the suggested solution is feasible (as demonstrated by other tourism locations) and to provide different types of benefits for all participants. The presence itself of a digital ecosystem may lead to a surge in demand for accessible tourism, enabling participating actors to understand the size and potential of this market.

However, while the digital ecosystem represents a valuable driving force to harmonise information provision and reduce information asymmetry, it is clear that the full deployment of accessible tourism requires adequate public and private facilities and investment. In addition, true commitment of actors to engaging in successful experience co-creation is fundamental, thus making the technical and cultural training of staff fundamental.

A further recommendation for both tourism destinations and operators is to enable accessible tourism experiences by adopting a universal design, that is, considering and creating experiences that can be used by all people, with or without specific access requirements. The COVID-19 crisis has provided tangible support to Darcy and Dickson's (2009) statement that everyone at some stage in their lives will have some temporary or permanent access requirements. In the lockdown (and post-lockdown) stages of the pandemic, many people (including tourists) in many countries around the globe have experienced access requirements. The use of an effective universal design approach to accessible tourism would also offer viable responses in such cases.

Overall, the solution suggested in this paper clearly represents only a first step and requires future empirical analyses based on real implementations to assess its strengths and weaknesses. Tourism locations that have begun planning and implementing similar solutions may then act as benchmarks and offer examples of best practices to highlight the feasibility and value of the suggested processes. Academic research can offer a valuable contribution to the development of accessible tourism. First, future studies should provide in-depth exploration of the attitudes and behaviours of digital ecosystems' actors (e.g. tourists, tourism operators) and assess the drivers of their willingness and disposition to engage in co-creation. Second, the outcomes of these co-creation processes should be evaluated. Third, research should provide a comprehensive framework of the factors influencing the success of digital ecosystems in fostering accessible tourism. For both theory and practice, creating harmonious universally accessible tourism ecosystems enabled by technology remains in its inception, but it is necessary to progress rapidly towards cocreating accessible tourism.

\section{References}

Akaka, M.A. and Vargo, S.L. (2014), “Technology as an Operant Resource in service (eco) systems”, Information Systems and e-Business Management, Vol. 12 No. 3, pp. 367-384.

Alén, E., Domínguez, T. and Losada, N. (2012), "New opportunities for the tourism market: senior tourism and accessible tourism", in Kasimoglu, M. (Ed.), Visions for Global Tourism Industry: Creating and Sustaining Competitive Strategies, InTech, Rijeka, pp. 139-166. 
Altinay, Z., Saner, T., Bahçelerli, N.M. and Altinay, F. (2016), "The role of social media tools: accessible tourism for disabled citizens", Journal of Educational Technology and Society, Vol. 19 No. 1, pp. 89-99.

Åstrøm, J.K. (2020), "Why theming? Identifying the purposes of theming in tourism”, Journal of Quality Assurance in Hospitality and Tourism, Vol. 21 No. 3, pp. 245-266.

Baccarani, C. and Cassia, F. (2017), "Evaluating the outcomes of service ecosystems: the interplay between ecosystem well-being and customer well-being", TQM Journal, Vol. 29 No. 6, pp. 834-846.

Baccarani, C., Cassia, F., Rossato, C. and Cavallo, D. (2019), "Territory, firms and value co-creation synergies", Journal of Place Management and Development, Vol. 12 No. 2, pp. 197-208.

Barile, S., Ciasullo, M.V., Troisi, O. and Sarno, D. (2017), "The role of technology and institutions in tourism service ecosystems", The TQM Journal, Vol. 29 No. 6, pp. 811-833.

Barnes, T.J. (2004), "Placing ideas: genius loci, heterotopia and geography's quantitative revolution", Progress in Human Geography, Vol. 28 No. 5, pp. 565-595.

Bourdeau, B.L., Cronin, J.J. Jr and Voorhees, C.M. (2007), "Modeling service alliances: an exploratory investigation of spillover effects in service partnerships", Strategic Management Journal, Vol. 28 No. 6, pp. 609-622.

Bowtell, J. (2015), "Assessing the value and market attractiveness of the accessible tourism industry in Europe: a focus on major travel and leisure companies", Journal of Tourism Futures, Vol. 1 No. 3, pp. 203-222.

Buhalis, D. (2000), "Marketing the competitive destination of the future", Tourism Management, Vol. 21 No. 1, pp. 97-116.

Buhalis, D. and Darcy, S. (2011), Accessible Tourism: Concepts and Issues, Channel View Publications, Bristol.

Cabiddu, F., Lui, T.-W. and Piccoli, G. (2013), "Managing value co-creation in the tourism industry", Annals of Tourism Research, Vol. 42, pp. 86-107.

Campos, A.C., Mendes, J., Valle, P.O.d. and Scott, N. (2018), "Co-creation of tourist experiences: a literature review", Current Issues in Tourism, Vol. 21 No. 4, pp. 369-400.

Chandler, J.D. and Vargo, S.L. (2011), "Contextualization and value-in-context: how context frames exchange", Marketing Theory, Vol. 11 No. 1, pp. 35-49.

Chathoth, P., Ungson, G.R., Harrington, R.J. and Chan, E.S. (2016), "Co-creation and higher order customer engagement in hospitality and tourism services: a critical review", International Journal of Contemporary Hospitality Management, Vol. 28 No. 2, pp. 222-245.

Ciasullo, M.V. (2017), "Introduction to the special issue on managing service innovation and quality: a service ecosystem perspective", The TQM Journal, Vol. 29 No. 6, pp. 762-766.

Cranmer, E.E., tom Dieck, M.C. and Fountoulaki, P. (2020), "Exploring the value of augmented Reality for tourism”, Tourism Management Perspectives, Vol. 35, 100672.

Darcy, S. and Dickson, T.J. (2009), "A whole-of-life approach to tourism: the case for accessible tourism experiences", Journal of Hospitality and Tourism Management, Vol. 16 No. 1, pp. 32-44.

Darcy, S., McKercher, B. and Schweinsberg, S. (2020), "From tourism and disability to accessible tourism: a perspective article", Tourism Review, Vol. 75 No. 1, pp. 140-144.

Forlani, F. and Pencarelli, T. (2019), "Using the experiential approach in marketing and management: a systematic literature review", Mercati and Competitività, Vol. 3, pp. 17-50.

Foubert, L. (2018), "Men and women tourists' desire to see the world: 'curiosity'and 'a longing to learn'as (self-) fashioning motifs (first-fifth centuries CE)”, Journal of Tourism History, Vol. 10 No. 1 , pp. 5-20.

Gillovic, B., McIntosh, A., Darcy, S. and Cockburn-Wootten, C. (2018), "Enabling the language of accessible tourism", Journal of Sustainable Tourism, Vol. 26 No. 4, pp. 615-630. 
TQM

33,1

Gretzel, U., Sigala, M., Xiang, Z. and Koo, C. (2015), "Smart tourism: foundations and developments", Electronic Markets, Vol. 25 No. 3, pp. 179-188.

Gretzel, U., Zhong, L., Koo, C., Boes, K., Buhalis, D. and Inversini, A. (2016), "Smart tourism destinations: ecosystems for tourism destination competitiveness", International Journal of Tourism Cities, Vol. 2 No. 2, pp. 108-124.

Grönroos, C. (1990), Service Management and Marketing Lexington Books, Lexington Books, Lexington, MA.

Jorgenson, J., Nickerson, N., Dalenberg, D., Angle, J., Metcalf, E. and Freimund, W. (2019), "Measuring visitor experiences: creating and testing the tourism autobiographical memory scale", Journal of Travel Research, Vol. 58 No. 4, pp. 566-578.

Kang, G.D. and James, J. (2004), "Service quality dimensions: an examination of Grönroos's service quality model”, Managing Service Quality: International Journal, Vol. 14 No. 4, pp. 266-277.

Law, R., Chan, I.C.C. and Wang, L. (2018), "A comprehensive review of mobile technology use in hospitality and tourism", Journal of Hospitality Marketing and Management, Vol. 27 No. 6, pp. $626-648$.

Lemon, K.N. and Verhoef, P.C. (2016), "Understanding customer experience throughout the customer journey", Journal of Marketing, Vol. 80 No. 6, pp. 69-96.

Lusch, R.F. and Vargo, S.L. (2014), The Service-Dominant Logic of Marketing: Dialog, Debate, and Directions, M.E. Sharpe, Armonk, New York, NY.

MacInnis, D.J. (2011), “A framework for conceptual contributions in marketing”, Journal of Marketing, Vol. 75 No. 4, pp. 136-154.

Michopoulou, E., Darcy, S., Ambrose, I. and Buhalis, D. (2020), “Accessible tourism futures: the world we dream to live in and the opportunities we hope to have", Journal of Tourism Futures, Vol. 1 No. 3, pp. 179-188.

Naniopoulos, A., Tsalis, P. and Nalmpantis, D. (2016), "An effort to develop accessible tourism in Greece and Turkey: the MEDRA project approach”, Journal of Tourism Futures, Vol. 2 No. 1, pp. 56-70.

Normann, R. (2001), Service Management: Strategy and Leadership in Service Business, Wiley, Hoboken.

Nunkoo, R. and Ramkissoon, H. (2011), "Developing a community support model for tourism”, Annals of Tourism Research, Vol. 38 No. 3, pp. 964-988.

Nyanjom, J., Boxall, K. and Slaven, J. (2018), "Towards inclusive tourism? Stakeholder collaboration in the development of accessible tourism", Tourism Geographies, Vol. 20 No. 4, pp. 675-697.

Park, S. and Santos, C.A. (2017), "Exploring the tourist experience: a sequential approach", Journal of Travel Research, Vol. 56 No. 1, pp. 16-27.

Pencarelli, T. (2019), The Digital Revolution in the Travel and Tourism Industry, Information Technology and Tourism, pp. 1-22, doi: 10.1007/s40558-019-00160-3.

Rosenbaum, M.S., Otalora, M.L. and Ramírez, G.C. (2017), "How to create a realistic customer journey map”, Business Horizons, Vol. 60 No. 1, pp. 143-150.

Rumetshofer, H. and Wöß, W. (2004), "Tourism information systems promoting barrier-free tourism for people with disabilities", in Miesenberger, K., Klaus, J., Zagler, W. and Burger, D. (Eds), International Conference on Computers for Handicapped Persons, Springer, pp. 280-286.

Saraniemi, S. and Kylänen, M. (2011), "Problematizing the concept of tourism destination: an analysis of different theoretical approaches", Journal of Travel Research, Vol. 50 No. 2, pp. 133-143.

Scheyvens, R. and Biddulph, R. (2018), "Inclusive tourism development", Tourism Geographies, Vol. 20 No. 4, pp. 589-609.

Sotiriadis, M.D. (2017), "Sharing tourism experiences in social media", International Journal of Contemporary Hospitality Management, Vol. 29 No. 1, pp. 179-225. 
Stone, M.J. and Petrick, J.F. (2013), "The educational benefits of travel experiences: a literature review", A way towards Journal of Travel Research, Vol. 52 No. 6, pp. 731-744.

Storbacka, K., Brodie, R.J., Böhmann, T., Maglio, P.P. and Nenonen, S. (2016), “Actor engagement as a microfoundation for value co-creation", Journal of Business Research, Vol. 69 No. 8, pp. 3008-3017.

United Nations (1975), Declaration on the Rights of Disabled Persons, United Nations, Geneva.

United Nations (2015), Transforming Our World: The 2030 Agenda for Sustainable developmentResolution, ARES/70/1, UN, New York, NY.

United Nations Statistics Division (2020), "Disability statistics", available at: https:/unstats.un.org/ unsd/demographic-social/sconcerns/disability/statistics/\#/countries.

UNWTO (2001), Global Code of Ethics for Tourism, United Nations World Tourism Organisation, available at: https://www.unwto.org/global-code-of-ethics-for-tourism.

UNWTO (2020), "Covid-19 and vulnerable groups", available at: https://www.unwto.org/covid-19inclusive-response-vulnerable-groups.

Vargo, S.L. and Lusch, R.F. (2004), "Evolving to a new dominant logic for marketing", Journal of Marketing, Vol. 68 No. 1, pp. 1-17.

Vargo, S.L. and Lusch, R.F. (2008), "Service-dominant logic: continuing the evolution”, Journal of the Academy of Marketing Science, Vol. 36 No. 1, pp. 1-10.

Vargo, S.L. and Lusch, R.F. (2016), "Institutions and axioms: an extension and update of servicedominant logic", Journal of the Academy of Marketing Science, Vol. 44 No. 1, pp. 5-23.

Vargo, S.L. and Lusch, R.F. (2017), "Service-dominant logic 2025", International Journal of Research in Marketing, Vol. 34 No. 1, pp. 46-67.

Vila, T.D., Darcy, S. and González, E.A. (2015), "Competing for the disability tourism market-a comparative exploration of the factors of accessible tourism competitiveness in Spain and Australia”, Tourism Management, Vol. 47, pp. 261-272.

WHO (2001), International Classification of Functioning, Disability and Health (ICF), available at: https://www.who.int/classifications/icf/en/.

WHO (2011), "World report on disability”, available at: https://www.who.int/disabilities/world_report/ 2011/report/en/.

Xin, S., Tribe, J. and Chambers, D. (2013), "Conceptual research in tourism", Annals of Tourism Research, Vol. 41, pp. 66-88.

\section{Corresponding author}

Fabio Cassia can be contacted at: fabio.cassia@univr.it

For instructions on how to order reprints of this article, please visit our website:

www.emeraldgrouppublishing.com/licensing/reprints.htm

Or contact us for further details: permissions@emeraldinsight.com 